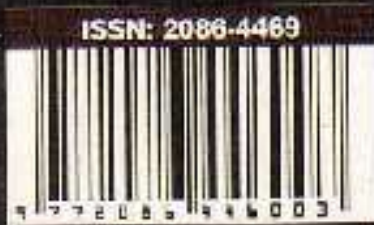

Volume 04 / Nomar 02 Juni 2013

\section{PEDAGOGIKA} Jurnal Ilmu Pendidikan
EDUCATION INFORMATION SYSTEMS PLANNING PRACTICES AND PERFORMANCE OF GOVERNMENT AGENCIES IN MALAYSIA

Hisyam Harun Mohd Khairuddin Hashim

MANAJEMEN PROGRAM PAKET B SEBAGAI PROGRAM PAUDNI PADA SANGGAR KEGIATAN BELAJAR DI KOTA GORONTALO Abdul Rahmat UNDERSTANDING MOTIVATION Harni Jusuf

PENGGUNAAN MEDIA KARTU GAMBAR DALAM MENUMBUHKAN MINAT MEMBACA PERMULAAN DI SEKOLAH DASAR KELAS AWAL

Evi Hasim

MENINGKATKAN KEIERAMPILAN MENUUIS KARANGAN SEDERHANA MELALUI PERMAINAN DESKRIPIF PADA SISWA KELAS III SDN I SUWAWA KABUPATEN BONE BOLANGO Ratnarti Pahrun MENINGKATKAN HASIL BELAJAR SISWA PADA MAGNET MELALUI METODE DEMONSTRASI (SUATU PENEUITIAN DI SDN 02 DILONIOYOHU) Djolin Mokoginta

STRATEGI MENUMBUHKAN MOTIVASI BELAJAR PESERTA DIDIK DI SMP NEGERI 3 LIANG KECAMATAN LIANG KABUPATEN BANGGAI KEPULAUAN Awaldin Lambause

PROFESIONALISME GURU TANTANGAN DAN SOLUSI Abdurrahman R. Mala KEBIJAKAN DESENTRALISASI PENDIDIKAN NASIONAL DALAM OTONOMI DAERAH Rustam Tohopi

UII KOMPETENSI GURU Antara Utopia Dan Harapan Yusniwati Lasahidido MOTIVASI DAN PERILAKU PARIMISATA BERKELANJUTAN DALAM PERSPEKTIF PSIKOLOG PENDIDIKAN Aniek Nurhayati

PENERAPAN MODEL PEMBELANARAN KOOPERATIF TIPE JIGSAW DALAM MENINGKATKAN EMAHAMAN MAHASISWA PADA MATA KULIAH BIMBINGAN DISI GSD

Salma Halldu PENGEMBANGAN PROGRAM STUDI DANA PNBP TAHUN ANGGARAN 2012 Murhima A. Kau 


\section{PEDAGOGIKA}

\section{Jurnal Ilmu Pendidikan}

ISSN: $2086-4469$

Volume 04 Nomor 02, Edisi Juni 2013

\section{Susunan Redaksi}

Penasehat:

Dekan Fakul:as IImu Pendicikan Universitas Negen Gorontalo

(Prot, Dr.H.Aod.Haris Fanai, M.Fo.)

\section{Penanggung Jawab:}

Pemban'u Dekan I dan II

FakL tas Ilmu Pencidikan UNG

(Dra. Hj.Rena L. Madina, M.Pd.\& Prol.Dr.H Ansar, M.Si)

\section{Ketua Penyunting:}

Dr. Aboul Rahnat M.Pd

\section{Penyunting Pelaksana:}

Meylan Saleh, S.FC.M.Pd

Feuzan Utiarahman, S.Pd.M.Pd

Hasria M.Abdoel

Meylan Saleh, S.Pd. M.Pd

\section{Penelaah Ahli:}

Prof. Mohd Khairudcin Hashim, Ph.D (UUM Malaysia) Prof. Dr. H. Achmad Hufadz, M Ed (LPI Bandurg) Prot Dr. H. Tharrin Abdullah. MM (UNJ Jakarta? Prof. Dr. H Abo Haris Panai, M.Pd (UNG Gorontalo) Prof. Dr. H. Ansar, M Si (UNG Gorontalo)

Pelaksana Tata Usaha:

Sri Fridariyani, S.Pd Fachrizal Nursyamsu, S.IP

\section{Alamat Redaksi:}

Gedung FIP Lt. 1 Fakul tas IImu Pendidikan Universites Negeri Gorontalo 1. Uend Soesirman Nc. 06 Gorontslo 96128 Telp/Fax: $0435821125-821752$

Email: infopedagogike@gmail.com

\section{Diterbitkan oleh:}

Pedagogika Press

Fakuitas IImu Pencidikan Universitas Negei Gorontalo Dicetak oleh ideas Publishing, 081244384444
Segala puji bagi Allah yang karena rikmatnya, sempurnalan kabaikan. Dialah yang telah menunjukkan kita untuk rrelakukan semua ini. Kalau bukar karcna pemberian-Nya tidaklah kita memperoleh petunjuk. Saam sejahtera semoga terlimpah atas kekasih A an, sang penerang dunia dan kekasin kita Mu hammad SAW, salam juga terlimpan atas keluarga dan para sahabatnya serta mereka yarg meng kuti jejak-Nya dengan beik hingga nari klamet

Semsurnalah anugerah, Allah SWT, kin Pedagogka: Jumal IImu Pend cikan, Volume volume 04 Nomor 02, Ecis Juni 2013 hadir di hadapen pembaca audiman. Pedagogika ditarbitkan oleh Fakultas IImu Perdidikan Universitas Negeri Gorontalo. Dewal Redaksi mengundang pakar, semerhati, dan pelaksana pencicikan uncuk menyampaikan gagasan atau hasil-hasil pengalaman? penelitian ampiris di bidang peningkaten mutu percidikan. Gagasan atau pengalamanipenelitian honcaknya dituangkan dalam bentuk tulisan Imiah seperti dipersyaratkan pada Pefunjuk Penulisan Naskah pada halaman akhir Jurnal ini.

Jurnal Pedagogika Fakultas limu Pencidikan Unversitas Negeri Corontalo kall ini tamo I varıatuf, cengan tujuan untuk merr berikan wawasan yang oada gi rannya akan membentuk. pemahamar dan skap tentang filosof pendidikan secara proies cral.

Aknirnya kepada semua dinak yang merbantu terselesakennya jurna ini kan hatu-kan terima kash semoga amal kita sernua langsung maupun ticak, dibalas setimpal oleh Allah SWT.

Redaksi menyadari banwa diperlukan elaboresi eksistensi dan konsistensi dalam pengembangan ecsi yeng akan datang, dengan rasa keterbatasan dan kemampuan, penuls berharap tegur sapa dan kritik dan secken ap pembaca demi perhaikan selenjutnya

Redaks:

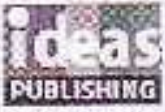




\section{DAFAR IS}

PFNGANTAR REDAKS|

DAF |AR IS|

EDUCATION INFORMATION SYSTENS PLANNING PRACTICES AND PERFORMANCEOF GOVERNMENT AGENCIES IN MALAYSIA

Hisysm Hann

Wohd Kharriddin Hashim

Coilege of Busitiess

Univorsiti Utara Malaysia

UNDERSTANDING MOTIVATION

Hami Jusuf

Dosen IAIN Sultan Amai Gorontsto.

HENGGUNAAN MEDIA KARTU GAMBAR DALAM MENUMBUHKAN MINAT MEMEACA PERMULAAN DI SEKOLAH DASAAR KELAS AWAL

Evi Hasim

Dossn PGSD FIP UNG. $1+6$

MENINGKATKAN KETERAMPILAN MENULIS KARANGAN SFDFRHANA MELALUI PERMAINAN DESKFIPTIF PADA SISWA KELAS III SDNI

SUWAWA.KAEUPAIEN BONE BOLANGO

Ratharti Puirun

Dosen FGSD FIP UNA 150

MENINGKATKAN HASIL BELAJAR SISWA PADA MAGNE MELALUIMETODE DENONSTRASI

(SUATUPENELITIAN DI SDN 02 DILONIOYOHU)

Dictis Miokoginta

Dosen L'niversitas Negeri Gorontato 156

STRATEGI MENUMBUHKAN MOTIVASI BELAJAR PFSER ADIDIKDI SMPNEGERI 3 LIANG KECAIVATAN LIANG KABUPATEN BANGGAI KEPIJ AUAN

Awaldin Lambeuse.

Dosen Fakutas Kegurusin dan Mmu Fendidikan Unrka Luwath

PROFFSIONALISME GURUTANTANGAN DAN SOLUSI AbourrahmatR. Walo

Dusen IAIN Suiran Amai Gorontaio 166

KEBIJAKAN DESENTRALISAS PENDIDIKANNASIONAL DAL AM OTONOMI LAERAH

Ristan Toiropi

Fedagog FEB Univorsitas Negeri Gorontato 170

UJI KOMFFTENSI GURU

Antara Utopia Den Herapan

Yusnimati Lasahiog

Doscn IAIN Sullan Amai Gorontalo

MOTIVASI DAN PERILAKU PARIWISATA BERKELANJUTAN CALAM PERSPEKTIF PSKOLOG PENDDIKAN

Aritek Neishavati

Dosen Fokutes Usribluddin IAW Sunan Amoei

182

$P=N E R A P A N$ MODEL PEMBELAJARAN KOOPERATIF TIPE JIGSAN DALAMIMENINGKATKAN PEMAHAMAN
MAHASISWA PADA MATA KULIAH BINBINGAN DI SI GSO

Sulme Haildu

Dosen Universitas Negen Gcrontaiu 187

PFNCEMBANGAN PROGRAM STUDI DANA PNBP TAHUN ANGGARAN 2012

inurbima A. Kâl

Dosen Universitas Negeri Gorontaic 193

PENTINGNYA PENDIDIKAN KARAKIER DIPERGURUAN

TINGSI

Suftatini Salingkat

PENERAPAN STRATEGI QUANTUM QUOTIENT DALAM MFNINGKATKAN PRESTASI BELAJAR PKN PESERTA DIDIK KELASVII DI SMPN 2 TOLI

Sippamo

Dosen Fakultas Kegunaan dan ilmu Pendidikon Liniversitas

Tompotika l whik 203

MANA.IEMEN PROGRAM PAKET B SEBAGA PROGRAM PAUDNI PADA SANGGAR KEGIATAN BELAJAR DI KOTAGORONTALO

Abdul Rabma!

Dosen Fakultas limu Pendidikan Universitas Negeri Gorontalo 206

PENERAPAN PEMBELAJARAN BERBASIS NILAI DÁLAM MENINGKATKANMINAT BELAJAR MAHASISWA PADA MATAKULIAH QUR'AN HADITS

Rabmin T Hissain

Dosen durusen Pendidikan Agama !slan IAlN Suttan Amal Eorontaio

212

MENGENAL SIKAP PEMAI U PADAANAK USIADINI

Sitriah Saim Litina

Dosen Psikolooi Faktitas Tarblyah IAiN Sultan Amai

Gorontalo $2 \div 8$

PENGGUNAAN METODE PEMBELA.JARAN KOOPERATIF TEKNIK GROUP INVESTIGATION (GI) TERHADAP PENINGKATAN HASIL BELAJAR MAHASISWA PADA MATA KULIAH PKN

Eirnis limar

Dosen Unwersitas Negeri Gorontaio

ANALISIS MANAJEMEN PARTISIPASI MASYARAKAT TERI ADAP MUTULULUSAN DI SMPCOKRONMINOTO I UWLKKABUPAIEN BANGGAI

IWayan Sudane

Dosan Fakwitas Kogunnan dan limu Fendolikan Universitas Tomootika Llinwik

229

PENGARUH MEDIA PEMBELAJARAN DAN KECERDASAN LINGUISTIK TERHADAP KETERAMPILAN MENYINAK

Ylinita Hatibie

ANALISIS EKSERGI SIKLUS BINER DENGAN PEMANFAATAN BRINE BUANGAN CLLSTFR 5 AREA GEOTERMALLAHENDONG SUI AWVESI UTARA

Henora bich

-akutas Tekaik Universitas Negeri Gorontain Gorcintalo 


\title{
PENTINGNYA PENDIDIKAN KARAKTER DI PERGURUAN TINGGI
}

\author{
Suhartini Salingkat
}

\begin{abstract}
ABSTRAK
hodel pendidiken karakter yang ! unirtegrası dalam cembelajaran iebih inenekankan pada panilaisn proses. Yeitu dihatapkan seiglah welaiviproses pembelajaran mehasiswa menjadi iobih kreatif dan prúkitif, rusa ingin tabu yang tinggi, memiliki kcpeouliar, kompstetif.
\end{abstract}

\section{A. PENDAhuluan}

Dewasa ini pendidikan karaktar sargat dibutuhkan di lembaga formal, seperti disekolah dan juge diperguruan tingui, Pelaksanaan pendidikan karakter di sekolah meupun diperguruan tinggi be um berjalan cengan baik atau raksimal. Hal ini dapat dilihat cengen adarya tawuran antar sekclah, tawuran antar manasisswa maupun perkelaian masal dan berbagai kasus tingkatan moral lainrya. Nenunut Thonjas Lickona, ada scpuluh (10) tanca karakter generasi muda yang patut dicemaskan karena akan membuat suatu bangsa tenggelam calam kehancuran. Kesepuluh tanda tersebut adalah:

1. Vieningkatrya kekerasan di kalangan remaja.

2. Penggunaan bahasa dan kata yang memburuk.

3. Pengaruh peer-group yang kuat dalam tindak kekerasan

4. Meningkatnye perilaku merusak diri, seperti perggunaan narkoba, akohol dar scks bebas

5. Semakin kaburnya pedoman moral baik dan buruk,

6. Merurunnya etos keja,

7. Semakin rendahnya rasa hormat kepada orang tua dan guru,

8. Rendahnya rasa tanggungjawab individu dan warga regara

9 Nembucayakan ketidasjujuran dan

10. Adanya rasa saling curiga dan kebencian antara sesama.

Dari ciri-ciri tersabut pada dasarnya sudah terjadi di INDONFSIA baik dikota maupun didesa. Misalnya meningkatnya kekerasan dikalangan pelajar atau mahasiswa dapat dilihat dengan adenya tawuran dimanamara, baik di sekolah maupun tawuran antar mahasiswa. Contoh yang lain yang saet ini banyak digunakan atau dikonsumsi clen para oclajar dan mahasiswa ya tu narkoba serta minuman keras, yang tenlunya dapat merusak perilaku diri mereka. Kecernasan dengan rendahnya rasa hormat pada orang tua dan guru atau dosen juga sudah terjaci, hal in dapat dilinat dengan adanya dems yang selalu terjàdi dikalangan kampus misalnya para mahasiswa me akukan orasi oras yang tidak bermoral dan heretike Isi oras dar para manasisvea tdak lagi rasional karene banyak menggunekan banase atau kata - kata yang kotor atau buruk. Bakken para mahasiswa menuntut: agar pimpinan harus turur dan jabatarnya. Ketika tuntuter mereke idak dipenuh maka dengan scenaknya pare mahasisva memblokirkampus melarang soanya kegiatan perku ahan den re akukan pombakaran ban jan bokas dinalaman kampus dan melakukan anar kis yakni dengan menconet-coret dinding dan juga merusak fasil tes kampus. Ini serrua mencerminkan oahwa pendidikan di Indonesia hanya lebih saryak kekocnitifnye sa a yazu para pendidik hanya ebih memfokuskan pada pemterier peajaran tetapi lupe dengan tugas membimbing atau mendid k para siswa atau mahasiswa untuk be tingkeh laku yang baik. Ini uga bisa dikatakan guru atau dosen hiwny mengejar materi agar cepat selesai sehingga luca mendidiknya. Untuk. mengatasi hal tersebutmaka diharaokan pemerintah dapat memasukan pendidiken karakter pads perguruan tinggi. melalui mata kulah.

\section{B. PENGERTIANKARAKTER}

Merur.jt pusat Bahasa DEFDIKNAS karakter adalah bawaan, hati, jiwa, kepribadan, budi pekerli, perilaku, personalitas, sifat tebiat, tempramen, dan watak. Adaoun berkaraktor adalah berkepribadian, berperiakı, bersifat bewatak, dan bertabi at

Dan menurut pusat kurikulum BALITBANG KEMDIKNAS karakter adala' watak, tab at ahklak, atau kcproadian seseorang yang terbentuk dari hasil internalisas berbagai kebajikar (Vir ues) yang diyakini dan digunakan sebagai andesan untuk cara pandang, berpikir, oorsikep dan bertindak.

Dan menurut Prot. Styanto. Plod "Karakter adalah cera pikir dan per laku yang menjadi ciri khas sctiao individu untuk hidup dan bekerja sama, baik dalam ingkuo keh dupan ke uarga. rasyarakat, asrgse dan regara.

Berdasarkan beberaoa pengertien tersebut maka capat disimpukan bahwa karakter adalah meruoakan watak, perilaku, ahklak, atau kepribadian sesecrang yang diguna zan sabagai andasan untuk perpik r berskap dan bertindak

Menunt Prof. Suyanto Pnd terdapat \& pilar karakter yang berasal dari nilai-nilai luhur univer sa manusia yaitu 1. Cinta Tuhan dan segenavrya 2. Kamandirian dan tanggung awab, 3. Ju ur i amaneh: 4 hornat dan santur ; 5 Dermawan suka tolong menolong dan gotong royong I kerjasama; 6 . Percaye dir dan pekeria keras: 7 . Kepemimainan dan keadian . 8. Balk dan rendah hati; $\theta$. Toleransi, kedema an dan kesatuan. Sedangkan menurut SD. Westwood menekankan pentingrya eaem pilar karakter yang dikembangkan yei tu : 1. Nasa percaya dir (Trustworthiness) , 2. Rasa horma: (respect) 3. Rasa tanggung jawab (Responsibility) , 4 . Rasa kepedulian ! caring ): 5. Rasa kebangsaan (citizensnis) -6. Rasa keadilan (fairness) 


\section{PENGERTIAN PENDIDIKAN KARAKTER}

Pendidikan karekter menurut T. Ramli ( 2003 ), memiliki esensi dan makra yang sama dengan pendidikan mora dan pendidikan ahkiak tujuannya adalah membentuk pribadi anak supaya menjadi manusia yang baik, warga masyarakai dan warga negera yang baik. Pengertian dari pend dikan karakteradaah suatu s stem penanaman niail - nilai karakter kepaca warga sekoleh yang meliputi kemampuan-kemampuan pengetainan, kesadaran atau kemauan dan tincakas untuk melaksanakan nilai - rilai tersebut calam pendidikan karakter disekolah, semua komponen harus taribat termasuk komponen - komoonen pendidik itu sendiri yaitu isi kurikulum, proses pembe a aran, dan peni a an. Pengelolaen mata pelajaran, pengelolaan sekolah, oelaksanaa aktifitas atau kegiatan ko-kurkuler pemberdayaan serana dan prasarana, penbiayaan dan etos kera seluruh warga sekolah ? lingkungan.

Dan menurut pencapat para anli yang lain Pendidikan karakter adalah segala sesuatu yang dilaikukan guru atau dosen yang mampu mempengaruhi karakter pesera didk. Guru atau dosen membentu membentuk watak peserta didik. Hal ini, mencakup ketc adenan, bagaimana perilaku Guru atau dosen, cara Gurul dosen berbicara atau menyampaikan materi, bagaimana Gurui dosen berto eransi dalam berbagai hal lannya

Borciasarkar parbahasan diatas capat disimo 1 kan bakwa pendidikan karakter merupakan upaya-upaya yang dirancang dan claksanakann secara sistematis untuk membantu peseta did k memahami nilai - nilal perilaku manusia yang berhubungan dengan Tuhan Yang Maha Esa, diri sendiri sesama manusia lingkungan dan kebangsaan yang erwujud dalam pikiran, sikap, perasaan serkataan dan os rouatan norma - norma agama, hukum tatakrama, budaya dan adat istiadat

\section{PENDIDIKAN KARAKTER DI PERGURUAN TINGGI}

\section{Pencidikan karakter dalam UU SISDIKNAS}

"Pendidikan nasional berfungsi mengembangkan kemampuan dan membentuk watak serta peradaban bangsa yang bermartabat dalam rangka mencercaskan kehidupan sangsa, can bertujuan untuk oerkembargnya potensi peserta cioik ajar monjadi manusia (1) yang beriman dan pertekwa kepeda Tuhan Yang Maha Esa, (2) beranklakmulia, (3) sehat (4) berilmu, (5) cakap, (6) kreatif, (7) manciri (8) menjaci warga negarayang cenokratis serta beranggungiawab"

Bercasarkan fungs pendid kan nasiunal iersebul maka dapatlah e nyatakan bahwa oandikan karakter penting di laksanakan d lemaaga formal yakni Sekolah / Perguruar tinggi. Peserta didik tidak hanya dituntul untuk cerdas? pintar tetapi narus menuniukan mamusia yang beriman dan hertakwa serta serahklak mulia.

Pendidikan karake diperguruan tinggi merupakan tahapan pempentukan karakter yang tidak kalah pentingnya dar sambentukan karakter di tingkat sckolah. Fendikan karakter di Pergunian Tinggi merupakan kclanutan den pend cikan karakier di sekulan, Oleh karena itu soharuenye sotiap Pergucuan lingg harus memilik. pole pembenti kan karakter mahasiswa sesua dengan Visi dan Misi karakteristik d perguruan Tinggi masing - masing. Pendidrisan karakter d serguruan tingg perlu didesain secara utuh artinya, pada saa: mahesiswa memasukl wilayah baru sebagai mahasiswa baru di Fakultes, di Program Studi, kogiatan organisasi kamous, samoai lulus sebagei Alumni semuanye harus di desain secara utuh.

\section{E. TUJUAN PENDIDIKAN KARAKTER}

Tujuan pendidikan karakter ada ah mendorang ahirnya insan manusia yang berahklak mulia dengan begitu tumbuh calam karakter yang bak. Manusia akan tumbuh dengan kapasitas dan komitmennya untuk melakukan berbagai hal yang terbak dan melakukan segala cengan tenar, dan cenderung memiliki tujuan hidup. Pendidikan karakter yang éektif ditemukan dalam lingkungan pendicikan yang memungkinkan sernua peserta didik menunjukan potensi mereka untuk mencapai tujuan yang sangat penting ( Battistich, 2008). Menurut Hentags foundarion ( dalam Arismantoro, 2005 ) pcndidikan kerakter bertujuan membentuk manusia secara utuh ( holistik) yang bcrkarakter yaitu mengembangkan asoek fisik emosi, sosial, kreatifitas, spiritual, dan intelektual peserta dick secara optimal.

Untuk mencapai tujuan pendidikan karaktor menurut Krischenbaum (1995: 16) salah satu programyang harus dilakukan adelah pendid kan karakter, yang meliputi

1) Rasa hormat ( terhadap orang lain can diri serdiri menjaga hak milik dan lingkungan

2) Rasa tanggung jawao (terpercaya, jujur, dapat diandalken)

3) Rasa kasihan (suka merolong, bersahabat, empat, toleran dan manusiewil

4) Disiplin ( tekun, rajin)

5) Loyalitas

6) Keberanan

7) Etos kerja

Agar tujuan pendidikan diperguruan tingai dape: tercepai maka ciharapkan tujuh program yang dikemukakan olch Krischenbaurn tersebul depat diterapkan cengan beik Pragram ini dapat dimasukan pada pe aksanzan kegiaten mahasiswa bar, kegatan crgenisesi kampus ataupun dalam perkuliahan, sehingga dengan demisan para perguruan tinggi dapat melahirkan alumni yang cerdas dan berwatak atau berprilaku yang baik.

\section{F. MODEL ATAU PENDEKATAN PENDIDIKAN KARAKTER}

Model perdidikan karakter yang di tawarkan oleh Healea ( 2005 ) yatu dalam membentuk civisi kemahasiswaar yang be tanggungjawab untuk berbagyi macam program, kebijatan. can sumber daya yang terturgsi memoentuk pengalaman di pergur dan tinggi baci mahasiswa. Miselrye, unusan mahasiswa melip ti urusan peradilan, kegialan mahasiswa, kehicupan oeragama, layanan karier, konsultasi akadernik, ayanan masysrakan, dan lain - lain. Kemahasiswaten ci posiskan secara unik untek membantu setias usaha dalam osndidikan. karakler secara khusus model ini berokus aada pembentukan karakter dalam asisten yanc cilakuken oleh bagian kemahasiswaan kerana meroka yang akan mendarr pir gi mahras swa selema belajar d perguruan tinggi yang oada 
gilirannya akan mendorong pengernbangan karakter sesama mahasiswa

Mode pendidikan karakter yang terintegrasi dalam pembelajaran lebih menekankan aaca perilaian proses Yaitu ciharepkar sotelak melalui oroses pemoelajaran mahasiswa menjadi lebih sreat $f$ dar orduktif rasa ingin tanu yang tinggi, memiliki kepedulian, kompetelif.

Pendskatan yang diakukan selayaknya merupakan pendekatan holistik ( erintegrasi dan ters nkronisasi ) dimana pangembangan karakter di integrasikan can di interkoneksikan vada semua asoek yang ada dalam lingkungen perguruan tingg. Untuk itu perlu aca kolaborasi seluruh komponen yang ada di perguruan inggi, makasiswa, dosen, staff, dosen wali, serla komunitas lannya Penerapan nilai - nilai di perguruan tinggi hekdaknya sama pcrekanannye der gan bidang akademik pada umumnya Model atau pendekatan dapat beruoa dielog peradaban, problem solving dan sentuhan kalbu.

Strategi yang dapat dilakukan $p=n d i c i k$ untuk mengembangkar pend dikan karakter seoaca berikus:

1) Menerapkan metode belajar yang melibatkan partisipasi aktif mahasiswa yaitu metode yarg dapat meningkatken motivas karena seluruh dimens mian sia terlibal secara aktif de gan diberiketi mater pelajaran yang konkrat, bernilai serta relevan dalam konteks kehidupan.

2) Menciptakan lingkungan belajar yang kondtsif.

3) Memberikan pencidikan karakter secara eksplisit, sistematis, dan berkesinamoungen dengan meliaatkan espek knowng the good, loving the goad and acting the good.

4) Membanguin hubungan yang spotive can ponut perhatian da am satu keles di ng kungà perguruen tinggi. Yang pertama dan terpenting adala' behwe lingkungan perguruan tinggi harus berkarakterist k aman se ta seling percaya ourmat, dan perhatian pads kesejahteraan lairnya.

5) Mencip akan peluang bag rahas swa untuk menjadi aktif dan penuh makna termasuk dalam kehicupan di kelas serta lingkungan perguruar tingg harcs menjad lebin damokratis sekeligus temoat bagi mahas swa untuk membuat keputusan dan tincasanrya serta merefleks atas hasil tindakannya.

6) Mengajarkan keterampian sosial dar emosional secara esensial.

7) Tidak ada mahasiswa yang terabaikan.
Salan satu contoh pendekatan atau model yang dilakukan di U nivers tas Pendidikan Indonesia yakn:

1. Meningkatken kualitas perkuliahan Pendidikan Kewarganegaraan

2. Pendekatan atau model berbasis pembinaan, layanar, bimoingan, dan konseling baik melalui mata kuliah mau pun diluar perkulianan

3. Melalui KKN lematik.

\section{G. KESIMPULAN}

Berdasarkan fungsi pendidikan nasional tersebut maka dapatla' diryatakan bahvid pendidikan karakter penting di laksanakan dilembaga formal yakni Sekolah ? Porguruan tinggi. Peserta didik tidak hanya dituntut untuk cerdas i pintar tetap harus menunjtkan manusie yang beriman den bertakwa so ta berahklak mulia Pendekatan yang dilakukan selayaknya meruoakan pencokatan holistik (teintograsi dan tersinkronisasi) dimena pengembangan karakter di integrasikan dan di interkoneksikan pada semua aspek yang ada calam lingktingan oergurtan tinggi. diharapkan setelan melalui proses pembelajaran mahasiswa menjadi le uih kreatif dan produktif rasa ingin tahu yang tinggi, memiliki kenedulian, dan kompcetif 


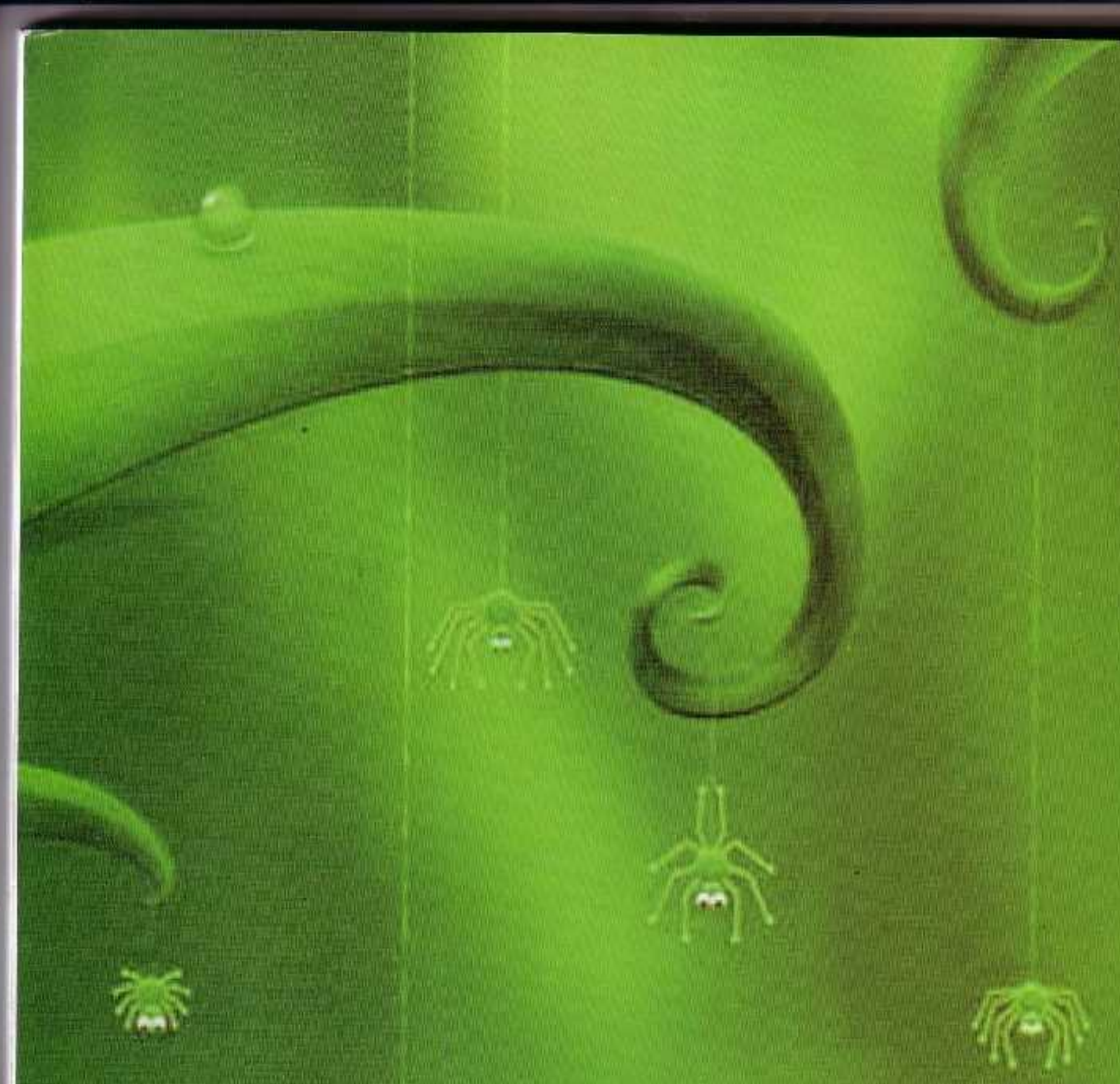

\section{PEDAGOGIKA}

Ain Jurnal llimu Pendidikan

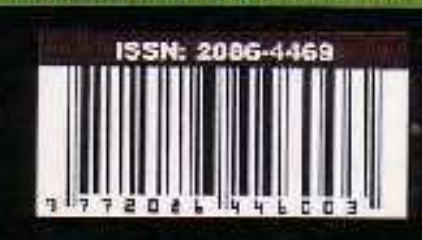

